\title{
Altiges
}

DOI: http://dx.doi.org/10.22483/2177-5796.2018v20n2p305-325

\section{Juventudes universitárias populares e educação freireana: reflexões sociológicas}

\author{
Adalberto Carvalho Ribeiro \\ Maria Natália Carvalho Alves
}

Resumo: Apresenta reflexões acerca da categoria freireana educação popular e fenômenos vinculados à juventude universitária brasileira. Nosso propósito é demonstrar que os universitários brasileiros, em boa medida e cada vez mais, têm origens sociais nas camadas mais populares, sugerir que para este tipo de juventude é a educação popular freireana a base conceitual mais próxima para compreender as vicissitudes deste grupo, e inferir que o ensino superior não está totalmente alheio às questões da juventude universitária popular e que a educação popular vem sendo aplicada neste universo. A escolha por universitários populares decorre de um fenômeno recente no Brasil denominado "massificação do ensino superior". A juventude, enquanto categoria carrega discursos dos mais díspares tanto que os sociólogos da juventude preferem utilizar a expressão "juventudes". O desafio é argumentar que a categoria educação popular se subsume perfeitamente aos fenômenos da juventude universitária popular brasileira. Os dados aqui trazidos têm como fonte pesquisas do Fórum Nacional do Pró-reitores de Assuntos Estudantis. Os resultados apontam que a massificação do ensino superior no Brasil é um fenômeno em andamento, que a universidade brasileira se popularizou e que parte dela utiliza a educação popular freireana como aporte teórico e fonte de diálogo com a juventude universitária popular.

Palavras-chave: Juventude popular. Ensino superior. Educação popular.

\section{Popular university youths and freireana education: sociological reflections}

\begin{abstract}
It presents reflections about the freireana category popular education and phenomena related to the Brazilian university youth. Our purpose is to demonstrate that Brazilian university students, to a great extent and increasingly, have social origins in the most popular strata, to suggest that for this type of youth Freirean popular education is the closest conceptual basis to understand the vicissitudes of this group, to infer that higher education is not totally alien to the questions of popular university youth and that popular education has been applied in this universe. The choice for popular university students stems from a recent phenomenon in Brazil called "massification of higher education". Youth, as a category carries discourses of the most disparate so much that sociologists of youth prefer to use the expression "youths." The challenge is to argue that the popular education category subsumes perfectly to the phenomena of Brazilian popular university youth. The data presented here is based on research from the National Forum of Pro-Rectors of Student Affairs. The results indicate that the massification of higher education in Brazil is an ongoing phenomenon that the Brazilian university became popular and part of it uses Freirean popular education as a theoretical contribution and source of dialogue with popular university youth.
\end{abstract}

Keywords: Popular youth. Higher education. Popular education. 


\section{Introdução}

Este trabalho apresenta algumas reflexões entre a categoria freireana educação popular e fenômenos vinculados à juventude universitária brasileira. O nosso propósito é: a) demonstrar que os universitários brasileiros, em boa medida, têm origens sociais nas camadas mais populares e que eles, em vários aspectos, carregam a marca de sua classe social, b) sugerir que para este tipo de juventude universitária é a educação popular freireana a base conceitual mais adequada para compreender as vicissitudes deste grupo, e c) inferir que o ensino superior não está totalmente alheio às questões da juventude universitária popular e que a educação popular vem sendo aplicada neste universo.

A escolha por universitários populares decorre de um fenômeno recente no Brasil, mas já consolidado na Europa, denominado "massificação do ensino superior" uma vez que ao acesso a este grau de ensino acorreu centenas de milhares de jovens especialmente nas últimas duas décadas. Esses jovens, de um modo geral, carregam consigo a "marca de classe" popular e a Universidade brasileira sendo acadêmica e erudita, como é a natureza dessa instituição desde quando fundada, sempre teve muitas dificuldades em dialogar e compreender as matrizes sociais culturais e populares dessa população específica.

A juventude, enquanto categoria inventada e construída, carrega discursos dos mais díspares. Considerando o fenômeno estudado, a noção conceitual precisa ser refletida com muito cuidado. Os sociólogos da juventude estão de acordo que é mais pertinente utilizar a expressão "juventudes", termo com o qual estamos de acordo.

Como Paulo Freire tinha uma preocupação com a causa popular, seria razoável admitir uma relação entre suas preocupações e a juventude escolhida para esta pesquisa. Entretanto, o ensino superior enquanto modalidade de ensino nunca foi objeto direto das reflexões freireanas. Nosso desafio é argumentar em favor dessa aproximação e defender que a categoria educação popular se subsome perfeitamente aos fenômenos da juventude universitária popular brasileira.

Os dados trazidos aqui são todos secundários. Têm como fonte os relatórios de pesquisa dos anos de 1996 e de 2014/2015 do Fórum Nacional do Pró-reitores de Assuntos Estudantis (FONAPRACE). Escolhemos algumas variáveis específicas que pudessem melhor revelar o perfil e as características da juventude universitária brasileira. Lembramos que o FONAPRACE pesquisou apenas os universitários das universidades federais brasileiras (IFES). 
Este trabalho está dividido em 5 seções, além desta introdução e das considerações finais. Na seção 2 mostramos um breve panorama conceitual da noção juventude. Os principais fenômenos que atingem a juventude são rapidamente escrutinados. A seção 3 traz o perfil e características específicas da juventude universitária nacional. Resolvemos recortar as informações dos relatórios FONAPRACE e apresentar informações que permitissem comparações entre o ano de 1996 e 2014/2015, considerando que nesse interregno se passaram 19 anos. Na seção 4 fazemos inferências sobre o pensamento de Paulo Freire e suas preocupações com o ensino superior destacando a categoria educação popular. Também aventamos a possibilidade da ocorrência da educação popular, como ferramenta teórico-prática, no âmbito da universidade brasileira. Em considerações finais retomamos nossos propósitos e mostramos, em síntese, as conclusões que chegamos.

\section{Juventudes: panorâmica conceitual}

A noção conceitual juventude não se deixa facilmente submeter aos constructos teóricos ou lógicas científicas. Uma das razões é que o próprio objeto de estudo vive em pleno movimento. "Construir uma definição da categoria juventude não é fácil, principalmente porque os critérios que a constituem são históricos e culturais" (DAYRELL, 2003, p. 41). Esta noção tem conquistado espaço nas discussões científicas e na agenda pública (SOUZA; PAIVA, 2012), a partir do século XIX e meados do XX, embora variando de um país para outro.

Juventude nunca foi um conceito dado e acabado, mas sim fruto de uma histórica representação específica dessa população, realizada seja no âmbito da comunidade científica, pelos formuladores de política públicas, ou no âmbito do senso comum. Não por acaso, a Organização das Nações Unidas para a Educação, a Ciência e a Cultura (UNESCO), não ficou de fora dessas preocupações e incorporou que o termo juventude deve considerar fatores relacionados a intensas transformações biológicas, psicológicas, sociais e culturais, que variam de acordo com as diferentes classes sociais, culturas, épocas, etnias, gênero, dentre outros aspectos determinantes (UNESCO, 2004 apud SOUZA; PAIVA, 2012).

Por não haver consensos, nem teóricos nem práticos, porque são muitas as variações (quanto a idade, origem social, região, religião, violência, hedonismo, entrada no mercado, autonomia, escolaridade, etc.), convencionou-se em parte da literatura especializada (ALVES, 
2008; ABRAMOVAY; CASTRO; WAISELFISZ, 2015; NUNES, 1968; DAYRELL, 2003; SPOSITO; TARÁBOLA, 2017; SOUZA; PAIVA, 2012) falar em juventudes, termo, inclusive, preferido por nós. Opção onde procuramos contemplar teórica e metodologicamente a juventude universitária popular brasileira.

Com a criação da Secretaria Nacional de Políticas de Juventude e do Conselho Nacional de Juventude pelo governo brasileiro, o critério para a população jovem passou a ser de 15 a 29 anos. Critério este que atende ao grupo de universitários aqui pesquisados.

Se levou em conta o aumento do tempo dedicado à formação escolar e profissional, a permanência maior com as famílias de origem, assim como as dificuldades para se conseguir, principalmente, o primeiro emprego. Características que definem a chamada geração Y, ou jovens nascidos a partir do início dos anos 1980 até o meio dos anos 1990 [...] (ABRAMOVAY; CASTRO; WAISELFISZ, 2015, p. 24, grifos nossos).

Dayrell (2003) entende que a juventude é, ao mesmo tempo, uma condição social e um tipo de representação. Este entendimento permite considerar a diversidade que engloba a noção de juventude. "Uma diversidade que se concretiza com base nas condições sociais (classes sociais), culturais (etnias, identidades religiosas, valores) e de gênero, e das regiões geográficas, dentre outros aspectos" (p. 42).

A definição acima, embora pareça vaga, tem utilidade para os propósitos deste trabalho. É que ao se pesquisar essa população específica é preciso considerar o que diz novamente Dayrell (2003, p. 43) "Meu contato com os jovens que pesquisei deixa muito claro o aparente óbvio: eles são seres humanos, amam, sofrem, divertem-se, pensam a respeito de suas condições e de suas experiências de vida, posicionam-se, possuem desejos e propostas de melhoria de vida".

A construção do termo juventude e suas primeiras definições científicas tem custado caro aos sociólogos da juventude.

Alves (2008), em relação à "invenção" da juventude, fez um balanço com base em vários autores (alguns deles: ARIÈS, 1988; LINCH, 1986; GAUTHIER, 2001; GALLAND, 1991; GUÉRIN-PLANTIN, 1999; GREEN, 1990; WALLACCE; KOVATCHEVA, 1998; MAUGER, 1994; MANNHEIM, 1990; DUBET, 1996; PAIS, 1993) sobre questões controversas que têm dividido os sociólogos da juventude.

Para uns, a juventude como idade de vida sempre existiu (GALLAND, 1991); para outros, "a juventude é socialmente construída e o seu aparecimento é um produto histórico da 
RIBEIRO, Adalberto Carvalho; ALVES, Maria Natália Carvalho. Juventudes universitárias populares e educação freireana: reflexões sociológicas.

modernidade (CRUZ et al. 1984; WALLACE; KOVATCHEVA, 1998; DUBET, 1996; PAIS, 1993)" (ALVES, 2008, p 17).

Para ela, a controvérsia decorre de dois equívocos:

O primeiro equívoco deriva do que, grosso modo, podemos designar por duas concepções distintas de juventude: uma que a concebe como uma classe etária, como um conjunto de indivíduos que pertence a uma mesma idade biológica; outra que a define como um grupo social cujo principal atributo reside no facto de os indivíduos que o integram estarem inscritos numa mesma fase de vida, serem confrontados com problemas sociais específicos e partilharem modelos culturais distintos dos adultos. $\mathrm{O}$ segundo equívoco decorre do processo de massificação da juventude. Com efeito, se é verdade que expressões como jovens e adolescentes fazem parte de um património linguístico europeu ancestral, é igualmente verdade que, durante séculos, esta fase de vida foi um privilégio de grupos sociais específicos - primeiro a aristocracia, depois a burguesia - e que só com a modernidade se verifica a generalização desta fase de vida, dando origem ao que tem vindo a ser designado por juventude moderna. É, precisamente, o atributo moderna utilizado para qualificar a juventude, que permite estabelecer as pontes entre duas posições, que só aparentemente se opõem, distinguindo entre uma experiência juvenil socialmente circunscrita e uma experiência juvenil massificada, característica das sociedades modernas (ALVES, 2008, p. 17-18, grifos nossos).

Concordando com Alves partilhamos da ideia de que seja como fase de vida, seja como experiência juvenil, a juventude moderna é "um produto da modernidade".

Com efeito, será no limiar da modernidade, no século XIX, que problemas referentes a “delinquência, imoralidade, prostituição, exploração econômica" vinculados ao jovem operariado ou filho de operário, que a construção social da juventude comportaria, em si, uma "marca de classe". Esta é uma referência importante porque nem sempre foi $\operatorname{assim}^{1}$ e porque os jovens aqui estudados oriundos da periferia do Brasil e filhos de segmentos pobres da sociedade, carregam também essa marca, como se verá adiante. Com a modernidade, portanto, "Juventude e problemas sociais são, assim, duas expressões que passam a ser indissociáveis e a integrar os discursos científicos, políticos e do senso comum” (ALVES, 2008, p. 24).

Uma primeira definição científica acerca de questões da juventude vem da Psicologia a partir da noção de adolescência no início do século XX, nos Estados Unidos, de autoria de Stanley Hall: adolescência definida como um período problemático e conturbado, durante o qual

${ }^{1}$ [...] discursos, decisivos na construção social da juventude, irão oscilar entre duas representações distintas: uma que concebe os jovens como a força motriz da mudança social; outra que coloca a tónica nos problemas que lhe estão associados. [...] No caso da juventude aristocrática, é a identificação do seu excessivo abandono aos prazeres mundanos que, nos finais do século XVII e início do século XVIII, está na origem de vários tratados sobre a sua educação (ALVES, 2008, p. 20).

Quaestio, Sorocaba, SP, v. 20, n. 2, p. 305-325, ago. 2018 
os adolescentes são confrontados com um conjunto de transformações biológicas e experimentam emoções que não controlam e que dificilmente compreendem.

A juventude como propriedade do indivíduo (uma outra noção) contrapõe-se à noção de juventude como "grupo de idade". Esta, uma definição que se apresentou fortemente controversa e tem sido objeto de numerosas críticas (ALVES, 2008).

Estamos, por outro lado, de acordo com Nunes (1968, p. 85-86), que já se referia à juventude como uma constelação de "meios sociais juvenis" e defendia a existência não de uma, mas de várias juventudes: uma ou mais juventudes burguesas, uma ou mais juventudes operárias. “Ora, é precisamente nesta clivagem entre a unidade da juventude, por um lado, e a sua diversidade, por outro, que radica uma das principais diferenças entre as várias teorias da sociologia da juventude" (ALVES, 2008, p. 31). Para o propósito deste trabalho "constelação de meios sociais juvenis" e a ideia de várias juventudes são interpretações mais apropriadas, ainda mais quando lidamos com uma juventude oriunda de meios populares do Brasil.

Ao compilar teoricamente a questão da juventude Alves (2008 cita PAIS, 1993, p. 37) mostrando que ele propõe o agrupamento das várias teorias da juventude em torno de duas grandes correntes: a) a geracional e b) a classista.

$\mathrm{Na}$ geracional estão a teoria das gerações e as teorias de cunho estruturo-funcionalistas dos anos 50 e 60. Esta primeira corrente se inscreve no quadro teórico mais abrangente das teorias da socialização.

A corrente classista, de matriz marxista, opõe-se à ideia da homogeneidade questionando a pertinência de um conceito de juventude que recorre à idade. Aqui, a classe social continua a ser a variável social mais importante para explicar as diferentes trajetórias escolares e, consequentemente, as posições diferenciadas que os jovens ocupam na divisão social do trabalho (ALVES, 2008).

A partir da década de 1990, surge um conjunto de trabalhos (ROBERTS, 1995, 1996; FURLONG; CARTMEL, 1997; EGRIS², 2001; LAGRÉE, 2002), cuja filiação teórica impossibilita a sua inscrição quer na corrente geracional quer na classista. "O que une todos estes autores é, por um lado, a constatação de que as experiências de vida dos jovens se alteraram profundamente, nas duas últimas décadas" (ALVES, 2008, p. 33).

\footnotetext{
${ }^{2}$ EGRIS é a sigla que designa o European Group for Integrated Social Research. 
Esses estudiosos perceberam o surgimento de um novo fenômeno: o "prolongamento da juventude". Há, de fato, um consenso generalizado entre os sociólogos da juventude de que o prolongamento da juventude vem ocorrendo nas sociedades ocidentais, ainda que alguns refiram que ele não se desenrola de uma forma homogênea nem linear em todos os países (WALLACE; KOVATCHEVA, 1998; CAVALLI; GALLAND, 1995; VALLÉS, 1999). Outros (KRUGER, 1994, GALLAND, 1988) chamam a atenção para a forma diferenciada como ele ocorre quando a noção de juventude, como categoria social homogénea, é substituída por uma outra que faz ressaltar a sua heterogeneidade interna. E outros ainda (DUBET, 1987, JONES, 1995, PAIS, 1993, MAUGER, 1994), referem que há distinção conforme a origem de classe.

É que a tese do prolongamento da juventude só faz sentido sociológico quando analisada à luz da teoria do curso de vida que elegeu como objeto de estudo "as sequências de transições socialmente reconhecidas", os acontecimentos biográficos.

A tese do prolongamento da juventude se baseia em vários fenômenos (acontecimentos biográficos) mais recentes: a) aumento generalizado da idade em que os jovens dão por concluída a sua formação acadêmica b) demora na entrada para o mundo do trabalho, c) saída da casa dos pais prorrogada, d) compromissos conjugais tardios, e) prolongamento da condição de genitores.

No Brasil, a exemplo de outros fenômenos (econômicos, educacionais) poder-se-ia caracterizar o prolongamento da juventude como tardio. Parece que esse é o caso.

Alves (2008, p. 58), à guisa de ir concluindo o debate teórico entende que

[...] mais interessante do ponto de vista conceptual, do que este faseamento da juventude é, por um lado, a reflexão que se tem vindo a desenvolver sobre a descoincidência entre o que a comunidade científica define como os acontecimentos biográficos que conduzem à adultez e as percepções dos jovens e, por outro, a função social que a juventude como idade de vida desempenha no ciclo de vida dos indivíduos.

É que na contemporaneidade há uma crescente ideologia individualista decorrente do processo de individualização em curso, nas sociedades ocidentais, talvez por isso, os jovens rejeitem as definições que os adultos lhes impõem do que é ser adulto e reivindiquem para si o poder de se atribuir esse estatuto a partir de um conjunto de competências cujo domínio apenas eles podem aferir (ALVES, 2008). Cada vez mais o trabalho individual de construção do estatuto social de adulto pela juventude torna-se mais longo e complexo. Há muitas incertezas permeando a cabeça do jovem em projetar seu futuro. 
Em um contexto assim, a função social da juventude vive em constante transformação e ebulição. "O prolongamento da juventude transforma a experiência juvenil e confronta os jovens actuais com situações novas e a vários títulos paradoxais” (ALVES, 2008, p. 60). O processo de socialização da juventude contemporânea mudou completamente.

\section{Juventudes universitárias populares: perfil e características}

Os dados sobre o perfil e características da juventude universitária brasileira foram buscados nos relatórios de pesquisas do FONAPRACE, órgão vinculado à Associação Nacional dos Dirigentes de Instituições Federais de Ensino Superior (ANDIFES). O FONAPRACE vem realizando pesquisas com os universitários brasileiros desde a década de 1990: 1996, 2003, 2010 e a quarta e mais recente em 2014/2015. Para os propósitos deste trabalho escolhemos os relatórios das pesquisas feitas em 1996 e 2014/2015 a fim de verificar fenômenos mais atuais e mais antigos, comparando o decorrer de 19 anos. O relatório de 2014/2015 é mais rico e detalhado ${ }^{3}$, bem como melhor definido metodologicamente que os anteriores.

As seguintes variáveis foram as escolhidas: a) sexo, b) faixa etária, c) condição econômica, d) estado civil, e) graus de escolaridade dos pais, f) tipo de trajetória escolar, g) fonte de informações, h) dedicação a atividades extraclasse. Vejamos.

Quanto ao sexo, em 1996, já naquela ocasião, havia mais mulheres que homens matriculados nas IFES brasileiras, $51.44 \%$ para mulheres enquanto que eram 48,56\% de homens. Em 2014/2015, confirma-se o quadro de 1996. O sexo feminino continua com maior participação com 52,37\% . O movimento com tendência para a feminização do ensino superior ocorrida em outros países, também se apresenta no Brasil.

No que se refere à idade, em 1996 a média foi de 23,13\% anos com as mulheres um pouco mais jovens (22,99 anos) do que os homens (23,28 anos). Em 2014/2015, os dados trabalhados mais detalhadamente mostram que, independente da região de localização da IFES, a maioria dos graduandos se encontra na faixa etária de 18 a 24 anos, correspondendo esta faixa a 66,28\%, em média. Em seguida, a maior frequência se dá na faixa de "25 anos e mais”, com 33,14\%. A idade média dos universitários, de

\footnotetext{
3 Tanto que neste relatório vem, ao final, o caderno metodológico da pesquisa com as explicações sobre procedimentos e critérios utilizados. No relatório de 1997 não existem essas informações.
} 
um modo geral, se elevou para cerca de 24,5 anos em 2014/2015, sendo a feminina para 24,23 e a masculina para 24,87 .

As mudanças acima são significativas. São números que sugerem o maior acesso que a juventude passou a ter ao ensino superior na última década uma vez que houve explosão da oferta. Isto reforçaria a tese da massificação do ensino superior como fenômeno global, e que no Brasil encontra-se em andamento. Por outro lado, esse aumento de idade pode está também associado ao prolongamento da juventude em uma das suas vertentes: a permanência na vida escolar por mais tempo considerando as dificuldades de entrar no mercado de trabalho.

Em relação à condição econômica, em 1996, o FONAPRACE utilizando a escala da Associação Brasileira dos Institutos de Pesquisa de Mercado (ABIPEME) categorizou os estudantes e chegou à seguinte situação: 12,61\% dos alunos pertenciam à classe A, 43,11\% à classe B (portanto, 55,72\% poderia ser considerada classes altas e médias altas), e os segmentos mais baixos registraram $30,54 \%$ para a classe $C, 10,50 \%$ para a D e 3,25\% para classe E.

Os números do parágrafo acima levam ao entendimento de que na década de 1990, mesmo diante de um inicial processo de entrada de jovens populares nas universidades brasileiras, a maioria (55\%) ainda era oriunda das elites nacionais o que corrobora a tese da elitização do ensino superior público, naquela altura, nomeadamente nas universidades federais. Em 2014/2015, com a mudança de critério de pesquisa pelo FONAPRACE, se observa a distribuição da renda familiar dos estudantes por faixas salariais. Houve

[...] uma significativa evolução da proporção dos estudantes sem renda familiar ou com renda de até 3 salários mínimos. [...] Em 2010, essa proporção era de cerca de $40 \%$ do total, em 2014, chega a ser mais de $51 \%$ de todos os estudantes, e isso em um cenário onde aqueles que não possuem ou não declararam renda familiar mais que triplicaram em número absoluto (FONAPRACE, 2016, p. 7, grifos nossos).

Os números mostram a considerável transformação do perfil do estudante em termos de condições socioeconômicas de suas famílias, com uma elevação significativa da participação de estudantes com menor renda familiar. Conforme a pesquisa de 2014/2015 (FONAPRACE), no balanço geral, a renda familiar mensal per capita média dos universitários que ingressaram no ano de 2009 (ou antes) era de R\$1.208,60 sendo 
maior do que a renda dos que ingressaram nos anos subsequentes a 2009. Isto é, quanto mais recente o acesso mais baixa é a renda do universitário.

Quanto ao estado civil, na pesquisa de 1996, 12,14\% dos alunos referiram estar casados e 3,21\% viver com um companheiro(a) o que totaliza 15,35\%, portanto, havia 84,65 de solteiros. Genitores eram 12,17\%, sendo 68,40\% dos casados, 35,96\% dos que têm companheiro e 3,20\% dos que vivem sós. Em 2014/2015 (FONAPRACE, 2016), o estado civil revela que $86 \%$ dos universitários são solteiros, $9 \%$ casados, $4 \%$ têm união estável, 1,2\% é de separados e 0,13\% de viúvos. No decorrer de 19 anos, a realidade nacional não se alterou tanto, havendo pequena queda no número de casais de $\mathbf{1 5 . 3 5 \%}$ em 1996 para $13 \%$ e indicando que uma parte da juventude nacional mudou seu comportamento quanto aos planos de constituir família e prorrogou a decisão. Portanto, no Brasil, o fenômeno do prolongamento da juventude também vem se realizando, ainda que de maneira tardia.

Uma das variáveis mais importantes é, sem dúvidas, o grau de escolaridade dos pais dos universitários porque ela está associada à qualidade do capital cultural das famílias. Em 1996, 32,16\% dos pais e 26,9\% das mães tinham nível universitário completo, 20,29\% dos pais e $25,43 \%$ das mães o segundo grau, 33,99\% dos pais e $32,82 \%$ das mães o curso primário. Estes números, de modo geral, mostram que, de fato, ainda nos 1990 as IFES brasileiras eram marcadas por alunos cuja origem social pertencia aos estratos médios e altos da sociedade reiterando a tese da elitização do ensino superior, tão criticada. A variável renda, como se viu, está parelha com estes níveis de escolaridade. Todavia, em 2014/2015 (FONAPRACE, 2016), a situação se alterou significativamente. Os números nacionais mostram que $22.16 \%$ dos pais têm ensino superior completo e pósgraduação. Já as mães somam 28,65 com ensino de graduação e pós-graduação. No outro extremo com o Ensino Médio incompleto até os níveis mais baixos como "não alfabetizados" tem-se $43,03 \%$ para os pais e $37,72 \%$ para as mães.

O que a variável acima revela é que, no transcurso dos 19 anos, de fato, caiu o nível de escolaridade em 8,25\% dos pais, (do homem e da mulher), na média. E que se elevou a participação da juventude cujos pais não completaram o Ensino Médio, com o percentual de 40,37\%. É a constatação de que as IFES brasileiras vieram recebendo cada vez mais segmentos populares nos últimos anos. 
Em relação ao tipo de trajetória escolar, em 1996, 45,0\% de alunos eram oriundos da escola pública. Cerca de $54 \%$ dos alunos que cursaram a escola pública e de $58 \%$ oriundos de escola privada frequentaram curso pré-vestibular. São dados que reforçam a tese da elitização das IFES nos anos 1990. Por outro lado, em 2014, as IFES recebem um crescente número de alunos egressos de escolas públicas. Os dados gerais dizem que, em média, 60\% dos graduandos cursaram o ensino médio somente em escola pública; $3,86 \%$ cursaram a maior parte em escola pública; 4,49\% cursaram a maior parte em escola particular e 31,49\% cursaram o ensino médio integralmente em escola particular. São, portanto, olhando nos extremos, $63.86 \%$ com origem exclusivamente no sistema público e $35,98 \%$ no privado.

O relatório de 2014/2015 (FONAPRACE, 2016) ainda informa a faixa de ano de ingresso na universidade: 50\% entre os que ingressaram em 2009 ou antes deste ano eram oriundos somente da escola pública enquanto que o ingresso a partir de 2013 registra 64,53\%. O reverso só poderia ser a queda na proporção dos que cursaram o ensino médio somente em escola particular: de 39,65\% entre os que ingressaram em 2009 ou antes, para 27,97\% entre os que ingressaram em 2013 ou depois. Os dados refletem, portanto, que a medida em que nos distanciamos dos anos 1990 e chegamos à atualidade as IFES brasileiras receberam universitários de camadas econômicas cada vez mais populares.

Em 1996, dentre as fontes de informação mais citadas pelos universitários (sem maiores detalhes naquele relatório), estão o telejornalismo com 55,13\% em primeiro lugar, ficando menos da metade das citações para os outros meios de comunicação, jornal escrito com $26,12 \%$, revistas $12,71 \%$ e jornal falado com 3,80\%. Note-se que a internet sequer é citada na pesquisa de 1996. Em 2014/2015 (FONAPRACE, 2016), a situação muda radicalmente: de forma contundente a internet constitui o veículo primeiro de informação. De cada 10 universitários 9 se informam principalmente por meio da internet. São 90,37\% de registros neste quesito. A televisão é a segunda fonte, embora constitua o hábito de apenas $5,7 \%$. O rádio é raramente utilizado $(0,53 \%)$ e a mídia impressa (jornais impressos e revistas) constitui fonte de informação principal para apenas 1,93\% do total dessa juventude específica. Outras fontes de informação correspondem a 1,47\%. 
A variável acima é surpreendente. Revela uma completa mudança de hábito quanto à fonte de informação. O número impressionante de $90,37 \%$ torna o uso da internet algo "revolucionário" se comparado ao ano de 1996 quando 55,13\% se informavam pelos jornais de televisão.

Em relação à última variável escolhida, às atividades extraclasse, em 1996 o movimento religioso foi a mais citada das atividades sendo referida por $24,67 \%$ do total, seguida por atividades artísticas/culturais com 19,90\% e 15,02\% para movimentos comunitários. 41,79\% dos alunos informaram não ter participação em nenhuma organização social. Em 2014/2015 o relatório FONAPRACE mostra que cerca de 3/4 dos graduandos - 72,63\% - não participam de nenhuma organização.

O que mais chama atenção com os números da variável acima foi a elevação de $41,79 \%$ para $72,63 \%$ de universitários que não participam de nenhuma atividade extraclasse que se refira a associações coletivas, assim como o reduzido interesse (pelo menos, aparentemente) pela política partidária uma vez que somente $2,48 \%$ participam de partidos políticos. É uma pista que parece apontar para o fenômeno “individualização da juventude”.

Uma das ilações que fazemos é quando associamos as variáveis atividades extraclasse à fonte de informações com internet. Os relatórios consultados não permitem um raciocínio mais producente, todavia, é possível inferir o seguinte: considerando que estamos diante de uma geração conectada, com jovens cada vez mais "plugados 24 horas por dia, sem tempo nem interesse" em participar de atividades coletivas presenciais, não seria essa uma das causas de sua individualização?

À guisa de síntese, chegamos às seguintes continuações e transformações notadas para o período 1996-2014/2015:

a) Em relação ao sexo continua a tendência de feminização do ensino superior público federal no Brasil;

b) Quanto à idade, houve elevação, na média, tanto para mulheres como para os homens apontando algumas possibilidades, entre elas: a) jovens mais velhos que antes não acessavam o sistema passaram a fazê-lo fazendo parte da onda massificação do ensino superior (em andamento no Brasil), b) "explosão" da oferta considerando a forte demanda juvenil concluinte do Ensino Médio, c) por outro lado, este indicador permite inferir sobre a possibilidade do 
prolongamento da juventude via maior permanência do jovem no sistema educacional;

c) Em relação à origem econômica os números revelaram que, no transcorrer dos 19 anos, as IFES brasileiras receberam uma parcela significativa oriunda dos estratos mais pobres da população. A universidade pública federal brasileira se "popularizou";

d) Sobre a situação conjugal há uma relativa continuidade considerando uma pequena queda no percentual de casais. As possibilidades indicam para a prorrogação da decisão dos compromissos matrimoniais tendo como consequência maior longevidade na vida acadêmica um dos indicadores do prolongamento da juventude;

e) Quanto ao grau de escolaridade dos pais ficou claro que as IFES passaram a receber cada vez mais a juventude filha de pais com baixa escolaridade reforçando o fenômeno que estamos chamando de "popularização" da universidade brasileira;

f) O tipo de trajetória escolar corrobora as demais variáveis. Em 2014/2015, de cada 10 universitários 6 eram oriundos somente do sistema público de ensino, portanto, sugerindo mais uma vez que as IFES passaram por significativa transformação quanto ao seu principal usuário;

g) A variável "fonte de informação" revelou uma mudança drástica. De cada 10 universitários das IFES 9 se informam pela internet. Eles abandonaram a televisão como fonte de informação. É um fenômeno universal, ao que parece, e que aponta para uma geração de pessoas conectadas. É possível que associado a este comportamento esteja o fenômeno da individualização da juventude;

h) Quanto as atividades extraclasse, a juventude estudada se desinteressou ainda mais por participar de qualquer forma de organização coletiva. O percentual subiu para $72,63 \%$ parecendo indicar a pertinência das teses que advogam o processo de individualização da juventude nos tempos atuais.

\section{Educação freireana e ensino superior: a preocupação com as juventudes populares}

A obra de Paulo Freire é relativamente conhecida entre os professores. O nome de Paulo Freire ganhou um destaque muito popular. Na sua obra, segundo Pontual (2011, p. 2), "há uma profunda paixão pela liberdade humana e, ao mesmo tempo, uma rigorosa e sempre renovada busca de uma pedagogia emancipatória".

Paulo Freire criou um corpo de princípios epistemológicos bem original, uma filosofia de educação cuja pedagogia é voltada à prática, voltada para a ação transformadora. O ponto de vista de Paulo Freire era o dos excluídos, os dos condenados da Terra (PONTUAL, 2011). 
RIBEIRO, Adalberto Carvalho; ALVES, Maria Natália Carvalho. Juventudes universitárias populares e educação freireana: reflexões sociológicas.

Desde o início do seu constructo teórico, nas ideias de Freire permeava essa abnegação (e obsessão) por uma causa popular. Uma de suas mais importantes contribuições seria exatamente a noção de uma educação popular.

Brandão (2013, p. 11-13), especialista na obra de Paulo Freire, diz

A Educação Popular, originalmente chamada aqui no Brasil e na América Latina de Educação Libertadora, Educação Liberadora, opunha-se ao que Paulo Freire qualificava como Educação Bancária. Desde um primeiro momento, ela surge como uma proposta situada dentro de todo um processo e um movimento bastante mais amplo, que tomou o nome de Cultura Popular. Sem perder nos anos sessenta sua original vocação "libertadora", a Educação Popular toma este "novo nome" (que não existe ainda em Pedagogia do Oprimido, o livro de Paulo Freire) ao assumir como seus coautores e destinatários os sujeitos singulares, coletivos e comunitários as diferentes "gentes do povo" e, de maneira mais concreta, a esta gentes como "classes", ou como uma "classe social" (grifos nossos).

Quando a educação popular se volta para os estratos sociais mais baixos, para esses sujeitos singulares, ela está se referindo a gente como a juventude universitária brasileira que oriunda das camadas populares carregam consigo não somente a marca de classe, mas um "DNA" muito particular: àquele a que Paulo Freire sempre se referiu e preferiu.

É nesse quadro contextual cultural que a juventude universitária, sujeito desta reflexão, se molda às orientações de uma educação popular. É certo que a educação popular não se resume a um conjunto de procedimento metodológicos. "Ela surgiu como uma proposta de uma modalidade de ação transformadora em seu campo, ao agir sobre saberes e valores de pessoas e de suas consciências" (BRANDÃO, 2013, p. 16).

O próprio Paulo Freire é quem melhor pode definir a categoria que é forjada por meio de sua obra.

Entendo a educação popular como o esforço de mobilização, organização e capacitação das classes populares; capacitação científica e técnica. Entendo que esse esforço não se esquece, que é preciso poder, ou seja, é preciso transformar essa organização de poder burguês que está aí, para que se possa fazer escola de outro jeito. Em uma primeira "definição" eu a aprendo desse jeito. Há estreita relação escola e vida política (FREIRE; NOGUEIRA, 1993, p. 19, grifos nossos).

Gadotti (2007, p. 24), outro freireano, entende que a educação popular tem se constituído num paradigma teórico que busca colaborar com os movimentos sociais e os partidos políticos que expressam essas lutas. Diminuir o impacto da crise social na pobreza, dar voz à indignação e ao desespero moral do pobre, do oprimido, do indígena, do camponês, da mulher, do negro, do analfabeto e do trabalhador industrial. 
RIBEIRO, Adalberto Carvalho; ALVES, Maria Natália Carvalho. Juventudes universitárias populares e educação freireana: reflexões sociológicas.

Diante do exposto, perguntamos: as IFES brasileiras têm realizado algum esforço no sentido de compreender a herança cultural de dois terços de seus alunos para praticar com eles uma educação popular? Este trabalho não tem como escopo responder a esta questão especificamente senão fazer algumas ilações apontando pistas.

Uma observação preliminar: no legado de Paulo Freire, reflexões sobre o ensino superior nunca foram feitas de modo direto e objetivo. Ou seja, as contribuições freireanas não se ocuparam sistematicamente do ensino superior como um objeto específico de estudo. Romão ${ }^{4}$ (2013) tenta mostrar que Paulo Freire não deixou de considerar em seus estudos preocupações com o ensino superior.

Pode parecer estranho falar de Paulo Freire e a Educação Superior, porque ele ficou mundialmente conhecido, seja por sua obra escrita seja por suas intervenções no Brasil e em outros países, como um "educador de adultos", como um "educador dos movimentos sociais", como um educador da educação não-formal. Além disso, Paulo Freire não entrou, a não ser como epigrafe, como título de instalações (escolas. bibliotecas. centros acadêmicos etc.), na Academia, no sentido de suas ideias serem referência para a produção do conhecimento. É que, embora muito reconhecido como educador pelas universidades, os nichos mais avançados da pesquisa e os campos do conhecimento de maior prestigio não incorporaram seus fundamentos como científicos. "Paulo Freire é um grande intuitivo", dizem os scholars, mas, além de não ser portador de diplomas, é um autodidata e, como tal, apresenta limites, quando não "está superado", dizem, sem na verdade, o terem aplicado. Portanto, uma primeira abordagem da relação de Paulo Freire com a Educação Superior, mesmo que ele não tenha escrito qualquer coisa sobre este grau de ensino, o ethos freiriano perpassa toda a educação, seja em que grau for [...]” (ROMÃO, 2013, p. 95-96, grifos nossos).

$\mathrm{O}$ autor ressalta que, na verdade, Paulo Freire refletiu sobre a educação superior e sobre o papel dos intelectuais quando teceu considerações sobre o papel das universidades e dos intelectuais, em 1994, ao participar de um seminário, promovido pela Universidade Nacional Autônoma do México (UNAM), no qual, discutiu com pesquisadores daquela universidade (ROMÃO, 2013).

A entrevista de Beisiegel $^{5}$ (2013) para a Revista Lusófona de Educação ajuda a compreender o que seria esse distanciamento de Paulo Freire com a Academia e o estranhamento desta para com as suas formulações. Abaixo alguns excertos da entrevista.

\footnotetext{
${ }^{4}$ José Eustáquio Romão é mais um freireano, membro do Instituto Paulo Freire de São Paulo juntamente com Moacir Gadotti e outros acadêmicos.

${ }^{5}$ Celso Beisiegel dedicou-se aos estudos de Paulo Freire procurando entender sua contribuição para o ensino superior.
} 
RIBEIRO, Adalberto Carvalho; ALVES, Maria Natália Carvalho. Juventudes universitárias populares e educação freireana: reflexões sociológicas.

Eduardo Santos: Uma das críticas da Academia - e não apenas em relação a Paulo Freire - é que não há ou não havia cientificidade e profundidade naquilo que ele fazia.

Celso Beisegel: O Paulo chega a dizer que quem sabe informa aquele que não sabe daquilo que ele sabe, mas depois ele vai redesvelando aquele objeto junto com o processo de desvelamento realizado pelo seu educando. Tudo isso é vago: como você vai transformar isso em alguma coisa que tenha um estatuto científico? É complicado! Eu e o Paulo tínhamos um grupo constituído por nós, a Dotti, a irmã da Fátima, o Paulo, o Barretão, a Vera Barreto, para tentar desenvolver uma proposta que o Paulo Freire tinha recebido para trabalhar com os professores leigos. Lembro-me que, quando prosperou, Paulo disse: "Imaginem se a gente pegasse o Celso e lhe perguntasse: como é que você educa na Universidade?" Eu fiquei quieto com os meus botões - nunca procurei desenvolver diálogo nas minhas aulas! Eu estudei Weber. Então, explico para os meus alunos como é que se coloca a questão dos tipos ideais, como isso é utilizado na pesquisa, exemplos de sociólogos que realizam as propostas de Weber nas suas investigações. Dá para pensar, por exemplo, como é que a gente chega ao processo de mais valia com meus alunos universitários. É claro que eles não são explorados da mesma forma, pelo menos nem todos; não é fácil! [...] No que diz respeito à profundidade, não há nenhum exemplo melhor do que a proposta de Paulo Freire para entender a teoria formulada por Marx para a educação, muito mais do que o modo como os famosos educadores soviéticos a explicam (p. 171, grifos nossos).

A entrevista prossegue revelando a visão de Beisegel, que foi pró-reitor de graduação na Universidade de São Paulo (USP). O excerto ajuda a refletir sobre as possibilidades de uma educação popular no ensino superior.

Eduardo Santos: O senhor pensa que os princípios fundamentais da educação popular podem penetrar na educação superior?

Celso Beisiegel: Não sei se dá para colocar por aí, pelo menos eu nunca pensei nisso. O que eu tenho discutido com alguns colegas, e até em alguns cursos, é que aquilo que era a educação popular quando se começou a desenvolver este tipo de prática e de estudo invadiu a universidade, até uma universidade de elite como a Universidade de São Paulo.

Eduardo Santos: [...] o senhor diz invadiu...invadiu como objeto de estudos? Os temas da educação popular foram trabalhados com os alunos?

Celso Beisiegel: Eu enfrentei as questões como pró-reitor em 1990. Nós tínhamos que fazer um segundo vestibular para preencher $13 \%$ das vagas que não tinham sido preenchidas na universidade pelo vestibular, e porque, principalmente na USP, o curso de Pedagogia é o curso dos pobres. Deu para sentir a reação de alguns colegas, alguns até de esquerda, muito mais do que eu, mas o argumento e o sentimento é que a USP é uma universidade para alunos que têm condições de acompanhar aquilo que ela quer lecionar no nível em que os seus professores colocam os temas. Isso é absolutamente contrário àquilo que Paulo Freire defendia. Quando ele afirmava que era necessário partir dos conhecimentos dos alunos... mas que conhecimentos? Quais são os conhecimentos que os alunos têm de Física? Não se pode partir do conhecimento que eles têm no Ensino Médio! Então, é necessário ser sensível ao ponto de partida disponível nestes alunos que entram na universidade. Na USP existem três turmas nos cursos noturnos de Pedagogia, o que significa que aumentou consideravelmente o número de alunos que vêm da periferia, da escola pública, no ensino superior em geral aumentou muito em função do PROUNI. Há, hoje, jovens 
da periferia que colocam a possibilidade de entrar na universidade, o que não acontecia há algum tempo atrás. Esta é uma temática que em muitos aspectos é a temática da educação popular. Vou partindo daquilo que eu acho, que tenho que ensinar para um aluno no primeiro ano, num curso da sociologia da educação, não consigo coisa nenhuma. Não é só Paulo Freire que defende, é muita gente, que é preciso tomar como ponto de referência aquilo que o seu aluno é, e depois ir tentando chegar com ele a um nível aceitável na universidade. Isso não implica abandonar os mais capazes, eu sempre trabalhei de forma heterogênea, tenho alunos muito bons, e por isso não se pode nivelar por baixo; com bibliografia adequada e com envolvimento vamos conseguindo alguns resultados (p. 176, grifos nossos).

Ainda Beisiegel (2018), referindo-se desta feita às Cartas à Guiné Bissau (publicado em 1977/1978), endereçadas aos responsáveis pela educação popular na antiga colônia, afirma que elas alcançam outros níveis de escolaridade: eram recomendações dedicadas à formação das elites locais, vistas como provedores dos quadros da administração colonial. Neste livro Paulo Freire revela mais um exemplo dos procedimentos analíticos, para o ensino superior, que podem ser confirmados, já no Brasil, no seminário sobre Universidade e compromisso popular, ocorrido em 1986 na Pontifícia Universidade Católica (PUC), em Campinas. Na exposição intitulada “O Compromisso Popular da Universidade”, Freire analisou explicitamente questões específicas do ensino superior.

No seminário ocorrido na PUC, Freire qualificou o que entendia como o processo de identificação de uma universidade com os interesses do povo e que a "aproximação da universidade aos interesses das classes populares não poderia ser entendida como ausência de compromisso com o rigor e a competência” (BEISIEGEL, 2018, p. 13).

Com efeito, a questão se as IFES brasileiras têm realizado algum esforço no sentido de compreender a herança cultural da juventude popular do Brasil e se incorporou alguns princípios da educação popular já pode ser respondida: a resposta é sim e não, ao mesmo tempo. Primeiro, não podemos esquecer que a universidade brasileira atende a cursos em todas as áreas: ciências exatas, naturais, linguagens e humanas. Estas últimas, até por princípios epistemológicos estão mais afeitas às questões sociais e deveriam estar, ou estão mais abertas aos problemas dos universitários oriundos das camadas populares. Por isso, as nossas inferências se referem apenas à área de humanas.

Tanto Romão quanto Beisiegel lançaram pistas importantes a respeito das seguintes possibilidades: a) a de que Paulo Freire se ocupou com o ensino superior, b) que a educação popular se encontra dentro das IFES brasileiras e c) que alguns professores vêm fazendo esforços 
para minimizar o impacto entre a cultura popular da juventude universitária pobre e a cultura erudita e acadêmica do ensino superior.

Para a primeira possibilidade consideramo-la suprida porque a filosofia de educação freireana não tem fronteiras educacionais quando se trata de educação popular; afora isto, também restou comprovado as preocupações de Freire, de modo objetivo, com o ensino superior. A segunda está mais que comprovada pelas estatísticas aqui trazidas. E, a terceira, consideramos que vem ocorrendo dentro das universidades ainda que sem uma sistematização coletiva, salvo por intermédio de projetos pontuais.

As IFES, como vimos, são majoritariamente fechadas aos universitários populares porque seus conteúdos e procedimentos didáticos e pedagógicos, e seus agentes, não compreendem o "jeito" (como diria Paulo Freire) dessa camada da sociedade.

Entretanto, uma parte das universidades brasileiras vem se esforçando em estabelecer um diálogo com a juventude popular do ensino superior. Porém, o que se tem são professores simpatizantes ou estudiosos da obra de Paulo Freire que buscam aplicar a educação popular, seja de modo individual seja de modo coletivo, por meio de projetos específicos ou não, e que dão o tom da relação entre a universidade e os jovens populares.

\section{Considerações finais}

Retomando os propósitos deste trabalho é possível afirmar que a) as reflexões conceituais e os dados aqui trazidos, sem sombra de dúvidas, revelaram que a juventude universitária brasileira também passa por um processo de transformação e que ela tem majoritariamente origens cravadas nas camadas populares; b) a noção conceitual educação popular oferece uma boa base teórica para a compreensão do movimento da juventude estudada. Educação popular carrega consigo princípios epistemológicos cuja causa são os excluídos, situação exatamente da ampla maioria dos jovens universitários brasileiros; c) apesar do perfil erudito e acadêmico das universidades brasileiras a educação popular as invadiu. E o fez por meio da vida real a partir do fenômeno da massificação do ensino superior tendo como consequência o que estamos chamando de "popularização" do ensino superior brasileiro.

A juventude universitária brasileira é determinantemente popular, de origem social cuja renda per capita média representa um pouco mais de 1 (um) salário mínimo nacional e suas 
trajetórias escolares são preponderantemente e, exclusivamente, no sistema público de ensino.

Os fenômenos de classe, portanto, é uma de suas marcas. O prolongamento da juventude já chegou ao Brasil com os jovens permanecendo mais tempo no sistema educacional e adiando a decisão de contrair matrimônio.

O tema aqui proposto é complexo e, pelo que vimos nas questões teóricas, não serão facilmente esgotados, se é que serão. Mais pesquisas com esse recorte são necessárias e bemvindas a fim de se compreender melhor fenômenos específicos vinculados ao grupo social estudado.

\section{Referências}

ABRAMOVAY, Miriam; CASTRO, Mary Garcia; WAISELFISZ, Júlio Jacobo. Juventudes na escola, sentidos e buscas: por que frequentam? Brasília: Flacso-Brasil, OEI, MEC, 2015.

ALVES, Natalia. Juventudes e inserção profissional. Lisboa, Portugal: Educa, 2008.

BEISIEGEL, Celso Rui. O pensamento de Paulo Freire: suas implicações na Educação Superior Eduardo Santos e Manuel Tavares conversam com o Professor Celso Rui Beisiegel. Revista Lusófona de Educação, Lisboa, v. 24, n. 24, p. 165-180, 2013.

BEISIEGEL, Celso Rui. Educação popular e ensino superior em Paulo Freire. Educação e Pesquisa, São Paulo, v. 44, 104010, p. 1-19, mar. 2018.

BRANDÃO, Carlos Rodrigues. Educação popular antes e agora. Revista do Centro de Educação e Letras da Unioeste, Cascavel, v. 15, n. 1, p. 10-24, 2013.

CAVALLI, A.; GALLAND, O. Youth in Europe. Social change in Western Europe. London: Printer. 1995.

CRUZ, M. B. et al. A condição social da juventude portuguesa. Análise Social, Lisboa, v. 20, n. 81-82, p. 285-308, 1984.

DAYRELL, Juarez. O jovem como sujeito social. Revista Brasileira de Educação, Rio de Janeiro, n. 24, p. 40-52, set./dez. 2003.

DUBET, F. La galère: jeunes en survie. Paris: Fayard, 1987.

DUBET, F. Des jeunesses et des sociologies. Le cas français. Sociologie et sociétés, Paris, v. 28, n. 1, p. 23-35, 1996.

EGRIS - European Group for Integrated Social Research. Misleading trajectories: transition dilemmas of young adults in Europe. Journal of Youth Studies, Berlim, Alemanha, v. 4, n. 1, p. 101-118, 2001.

FONAPRACE. Fórum Nacional de Pró-reitores de Assuntos Estudantis, Associação Nacional dos Dirigentes das Instituições Federais de Ensino Superior Fórum Nacional de Pró-Reitores de Assuntos Comunitários e Estudantis. IV Pesquisa do Perfil Sócioeconômico e Cultural dos Estudantes de Graduação das Instituições Federais de Ensino Superior Brasileiras. Relatório. 2016.

FREIRE, Paulo; NOGUEIRA, Adriano. Teoria e prática em educação popular. 4. ed. Petrópolis: Vozes, 1993. Coleção Que Fazer. 
RIBEIRO, Adalberto Carvalho; ALVES, Maria Natália Carvalho. Juventudes universitárias populares e educação freireana: reflexões sociológicas.

FURLONG, A.; CARTMEL, F. Young people and social change. Individualization and risk in late modernity. Buckingham: Open University Press. 1997.

GADOTTI, Moacir. Paulo Freire e a educação popular. Proposta - Revista Trimestral de Debate da FASE, São Paulo, v. 31, n. 113, p. 21-27, jul./set. 2007. Disponível em: <https://fase.org.br/wpcontent/uploads/2007/09/proposta-113-final.pdf>. Acesso em: 5 mar. 2018.

GALLAND, O. Représentations du devenir et reproduction sociale: le cas des lycéens de d'Elbeuf. Sociologie du Travail, Paris, v. 30, n. 3, p. 399-417, 1988.

GALLAND, O. Sociologie de la jeunesse. L'entrée dans la vie. Paris: Armand Colin. 1991.

JONES, G. Leaving home. Buckingham: Open University Press, 1995.

LAGRÉE, J. C. Youth and post-modernity. In: LAGRÉE, J. C. (Ed.). Rolling youth, rocking society. Paris: Unesco, 2002. p. 15-43

KRUGER, H. La prolongation de la durée de la heunesse : un phénomène diffèrencié selon les sexes. In: MAUGER, G.; BENDIT, R.; WOLFFERSDORFF, C. (Ed.). Jeunesses et sociétés. Perspectives de la recherche en France et en Allemagne. Paris: Armand Colin, 1994. p. 78-94.

MAUGER, G. Les jeunes en France. État des recherches. Paris: La Documentation Française, 1994.

NUNES, A. S. Sociologia e ideologia do desenvolvimento. Lisboa: Moraes Editores, 1968.

PAIS, J. M. Culturas juvenis. Lisboa: Imprensa Nacional, 1993.

PONTUAL, Pedro de Carvalho. Contribuições de Paulo Freire e da educação popular à construção do sistema educacional brasileiro. Revista e-curriculum, São Paulo, v. 7, n. 3, edição especial de aniversário de Paulo Freire, dez. 2011. Disponível em: < http://revistas.pucsp.br/index.php/curriculum>. Acesso em: 10 mar. 2018.

ROBERTS, K. Youth and employment in modern Britain. London: Oxford University Press, 1995.

ROBERTS, K. Individualization and risk in Eastern and Western Europe. In: HELVE, H.; BYNNER, J. (Ed.). Youth and life management. Research Perspectives. Helsinki: Helsinki University Press, 1996. p. 226-240.

ROMAO, José Eustáquio. Paulo Freire e a Universidade. Revista Lusófona de Educação, Lisboa, n. 24, p. 89-105, 2013.

SOUZA, Candida de; PAIVA, Ilana Lemos de. Faces da juventude brasileira: entre o ideal e o real.

Estudos de Psicologia, Natal, RN, v. 3, n. 17, p. 353-360, set./dez. 2012. Disponível em:

<www.scielo.br/epsic>. Acesso em: 29 mar. 2018

SPOSITO, Marília P.; TARÁBOLA, Felipe de S. Entre luzes e sombras: o passado imediato e o futuro possível da pesquisa em juventude no Brasil. Revista Brasileira de Educação, Rio de Janeiro, v. 22, n. 71, p. 1-25, 2017.

VALLÉS, M. Jóvenes españoles, jóvenes europeos a las puertas del siglo XXI. In: CACHÓN, L. (Ed.). Juventudes, mercados de trabajo y políticas de empleo. Valencia: Editorial 7 i Mig, 1999. p. 119-131.

WALLACE, C.; KOVATCHEVA, S. Youth in society. The construction and deconstruction of youth in East and West Europe. London: Macmillan Press. 1998. 
RIBEIRO, Adalberto Carvalho; ALVES, Maria Natália Carvalho. Juventudes universitárias populares e educação freireana: reflexões sociológicas.

\author{
Adalberto Carvalho Ribeiro \\ Universidade Federal do Amapá - UNIFAP | Departamento de \\ Educação \\ Macapá | AP | Brasil. Contato: adalb.cr@gmail.com \\ ORCID 0000-0002-5039-7179 \\ Maria Natália Carvalho Alves \\ Universidade de Lisboa - IEUL | Departamento de Educação \\ Lisboa | Portugal. Contato: nalves@ie.ulisboa.pt \\ ORCID 0000-0003-1764-6708
}

Artigo recebido em: 2 jul. $2018 \mathrm{e}$

aprovado em: 10 jul. 2018. 